\title{
Dialogando com Bakhtin: \\ algumas contribuiç̧ões para a compreensão das interações verbais no campo da saúde *
}

Guilherme Torres Corrêa ${ }^{1}$

Victoria Maria Brant Ribeiro²

CORRÊA, G.T.; RIBEIRO, V.M.B. Dialogue with Bakhtin: some contributions to the understanding of verbal interactions in the health field. Interface - Comunic., Saude, Educ., v.16, n.41, p.331-41, abr./jun. 2012.

Based on the idea that both the needs and interventions in health are human conditions and actions often permeated and built by communicative acts, this article discusses central categories of Mikhail Bakhtin's philosophy of language - such as: dialogue, utterance, gender and polyphony - and proposes their use as a framework for the analysis of verbal interactions in the health field. Bakhtin conceives language social in nature, understanding that the communication in every field of society reflects their specific purposes, historical and social conditions. According to him, the subject is constituted in a discursive manner, by means of appropriating other's voices, being also entirely social and unique. With reference to that social and unique constitution of individuals, the article also presents, in a seminal way, a practical proposition for the construction of spaces and activities in the health field.

Keywords: Bakhtin. Language. Communication. Verbal interactions. Health.
Com base na ideia de que as necessidades de, e as intervenções em saúde são condições e ações humanas permeadas e construídas, com frequência, por atos comunicativos, este artigo discute categorias centrais do pensamento do filósofo da linguagem Mikhail Bakhtin tais como: dialogia, enunciado, gênero e polifonia - como referencial para a análise de interações verbais no campo da saúde. Bakhtin desenvolve um pensamento cujo fundamento é a natureza social da linguagem, entendendo que a comunicação de cada época e de cada grupo social reflete as condições específicas e as finalidades dos respectivos campos da sociedade. Para ele, o sujeito se constitui discursivamente ao apreender vozes alheias e é integralmente social e singular. Tomando como referência essa constituição social e singular dos indivíduos, o artigo também apresenta, de forma seminal, uma proposição prática para a construção de espaços e de atividades no campo da saúde.

Palavras-chave: Bakhtin. Linguagem. Comunicação. Interações verbais. Saúde.

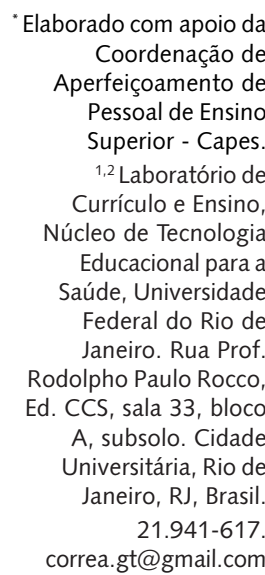


Este artigo pode ser entendido como a apresentação e a sistematização do pensamento de um autor, Mikhail Bakhtin, e suas possíveis contribuições ao campo da saúde. A ideia para a elaboração deste ensaio se concretizou após a busca em periódicos científicos das áreas de Saúde Coletiva e de Ensino e Educação em Saúde revelar que o autor não é referência frequente; mais que isso, os artigos que o tomam como guia, não desenvolvem uma proposta mais elaborada de dispositivo analítico, pois apenas aplicam sua teoria ao objeto de estudo em questão.

Bakhtin foi um filósofo e crítico literário russo que dedicou parte de sua vida intelectual à construção de uma teoria da enunciação, ou de uma teoria da linguagem, que nos permite olhar, de forma analítica, as interações discursivas nos diversos campos da atividade humana e da comunicação. É nesse sentido que entendemos a importância do pensamento de Bakhtin para o campo da saúde, uma vez que a comunicação está presente nos diferentes processos ou eventos que aí se desenvolvem. De maior relevância, para nós, é a compreensão de que as necessidades de, e as intervenções em saúde são condições e ações humanas permeadas e construídas, com frequência, por atos comunicativos. No que tange à discussão que nos propomos fazer, não é necessário, a princípio, definir o campo, ou escolher um conceito consagrado de saúde, independentemente do seu viés (biomédico, ambiental, social etc.), pois o debate dessa questão dependerá do espaço, do momento ou da situação em análise.

Para fins de elaboração da proposta, damos prioridade (não exclusividade) a espaços, momentos ou situações que envolvam atividades e processos de educação em saúde, a relação profissional-paciente e as narrativas e experiências de saúde, adoecimento e cuidado, o que não é pouco, tomando todos os sujeitos aí envolvidos. Não exploramos essas atividades e processos em sua totalidade, mas apenas algumas situações-modelos para que aqueles interessados em nossa proposta possam fazer uso quando e onde acharem apropriado. Construímos um quadro de categorias analíticas que permite dialogar com situações que imaginamos potenciais.

As referências nas quais nos baseamos para construir a proposta são: o livro "Marxismo e filosofia da linguagem" (1981), o artigo "Discurso na vida e discurso na arte: sobre a poética sociológica", e os textos "Os gêneros do discurso", "O problema do texto na linguística, na filologia e em outras ciências humanas" e "Metodologia das ciências humanas", presentes no livro "Estética da criação verbal" (2003), todos de autoria do próprio Bakhtin ${ }^{3}$, além de dois textos de outros autores que o tomam como referência (Fiorin, 2006; Amorim, 2002).

Lembramos que o objetivo deste trabalho não é fazer uma revisão e o estudo das contribuições dos principais pensamentos e vertentes sobre linguagem/ discurso/comunicação no século XX, momento em que essa discussão ganhou maior destaque e fundamentação teórica, sobretudo no campo da filosofia (no qual se encontra Bakhtin), por exemplo, com Gadamer, Habermas, Foucault, Wittgenstein, Rorty e Derrida, entre outros.

Nosso enfoque centra-se mais na apresentação da riqueza das ideias de um autor em especial e na sua apropriação/aplicação a determinado objeto (fundamentalmente, as interações verbais em saúde), do que em tratar do debate sobre linguagem/discurso/comunicação desenvolvido no último século e suas consequências para o campo da saúde, apesar de termos interesse no assunto e julgá-lo de relevância inquestionável.

\footnotetext{
${ }^{3}$ Não há consenso sobre a verdadeira autoria das obras atribuídas a Bakhtin, mas diversos estudiosos consideram Bakhtin como, pelo menos, coautor dessas obras.
} 
${ }^{4}$ Bakhtin parece não abandonar o pensamento marxista em sua totalidade ao longo da vida, mas é evidente que deixa de tomá-lo como referência explícita em suas obras subsequentes ao "Marxismo e filosofia da linguagem".

\section{Subsidiando a proposta}

Um dos fundamentos do pensamento bakhtiniano é a natureza social, dialógica, da linguagem, o que ganha importância central para nossa proposta, uma vez que a comunicação se dá pela linguagem - o instrumento de mediação entre o homem e a natureza e dos homens entre si.

Na percepção de Bakhtin, falar sobre consciência é falar sobre linguagem, pois a consciência só pode surgir e se afirmar como realidade por meio da encarnação material em signos. A própria linguagem e os signos não existem apenas como parte de determinada realidade, mas também refletem e refratam outra, já que estão sujeitos aos critérios de avaliação ideológica, ligados a uma visão de mundo. Assim, compreender um signo é aproximar o signo apreendido de outros já conhecidos, sendo a compreensão uma resposta a um signo por meio de signos, uma cadeia semiótica de criatividade e de compreensão ideológica única e contínua. Portanto, a consciência só se torna consciência quando se impregna de conteúdo ideológico e somente no processo de interação social, na assimilação de discursos alheios. Para Bakhtin, a consciência é um fato socioideológico, e sua lógica é a da comunicação ideológica, da interação semiótica de um grupo social.

Fundamentado no pensamento marxista ${ }^{4}$, Bakhtin acredita que as relações de produção e a estrutura sociopolítica que delas derivam determinam os contatos verbais, as formas e os meios de comunicação verbal possíveis entre indivíduos, e é das condições, formas e tipos de comunicação verbal que derivam tanto as formas como os temas dos atos de fala. Sob uma perspectiva de luta de classes, a classe dominante tende a conferir ao signo ideológico um aspecto intangível e acima das diferenças de classe, com o objetivo de abafar ou de ocultar as contradições que aí se travam, a fim de tornar o signo monovalente. O signo se torna uma arena onde se desenvolve a luta de classes, mesmo que classes sociais diferentes façam parte da mesma comunidade semiótica - por exemplo, uma língua nacional, porque, nesse espaço, se confrontam visões de mundo contraditórias.

Um profissional com visão estritamente técnica e biológica dos processos de saúde-doença-cuidado e que, ao conversar com um paciente, apenas aborde questões relacionadas ao seu comportamento, sem buscar entender o espaço em que ele vive, suas condições de vida e relações sociais, culpabilizando-o por sua situação, traduz, assim, uma visão de mundo em que o indivíduo é responsável por tudo aquilo que the acomete.

Para Bakhtin, a ideologia não é exterior ao semiótico, pois o domínio do ideológico coincide com o domínio dos signos: são mutuamente correspondentes. O signo ideológico tem vida na medida em que se realiza no psiquismo e a realização psíquica vive do suporte ideológico; o signo ideológico é o território comum, tanto do psiquismo como da ideologia. Concretamente, em toda enunciação, por mais insignificante que seja, renova-se sem cessar uma síntese dialética viva entre psiquismo e ideologia, entre vida interior e exterior. Todo signo ideológico exterior, independentemente de sua natureza, banha-se nos signos interiores, na consciência; a vida do signo exterior se faz por um processo sempre renovado de compreensão, de emoção e de assimilação em integração reiterada com o contexto interior. O pensamento de caráter cognitivo é materializado na consciência, no psiquismo, mas este se apoia no sistema ideológico de conhecimento que lhe é apropriado; portanto, o pensamento individual, desde sua origem, pertence ao sistema ideológico e subordina-se às suas leis, porém ele pertence simultaneamente a outro sistema único, com leis específicas, o sistema do psiquismo. Existe, assim, entre o psiquismo e a ideologia, uma interação dialética indissolúvel. 
Segundo Bakhtin, os processos de compreensão dos fenômenos ideológicos não podem se desenvolver sem a participação de um discurso interior (a consciência), o qual se faz pela palavra, o material semiótico da vida interior e o fenômeno ideológico por excelência. A palavra tem ubiquidade social, está em todas as relações entre indivíduos e, sendo assim, ela apresenta a característica importante de ser o indicador mais sensível das transformações sociais.

É nesse contexto que cabe diferenciar duas instâncias de ideologia abordadas pelo autor, sobretudo no sentido de compreender a ideologia por uma perspectiva dinâmica, de movimento, e não como algo estático, dado. Bakhtin faz distinção entre a ideologia oficial, aquela dominante, de estrutura e conteúdo mais ou menos estável, composta pelos sistemas ideológicos constituídos, como a ciência, a arte e a religião, e a ideologia do cotidiano, instável, do domínio da palavra interior e exterior desordenada e não fixada em um sistema ideológico constituído. Mas essas duas instâncias se relacionam dialeticamente, não são entes isolados; os sistemas ideológicos constituídos cristalizam-se com base na ideologia do cotidiano, e é aí que encontram sua forma viva e crítica. Há um vínculo orgânico e ininterrupto de um sistema ideológico constituído com a ideologia do cotidiano de determinada época - isso nos limites de um grupo social determinado. No entendimento de Bakhtin, a ideologia do cotidiano repercute as mudanças da infraestrutura socioeconômica e é capaz de acumular as energias criadoras que auxiliam na efetuação das revisões parciais ou totais dos sistemas ideológicos.

Entretanto, o autor lembra que, no decorrer do processo de infiltração progressiva nas instituições ideológicas (como a ciência, a literatura e a imprensa, entre outras), as novas correntes da ideologia do cotidiano, por mais revolucionárias que sejam, estão submetidas à influência dos sistemas ideológicos estabelecidos. Há, ainda, outra discussão sobre a ideologia do cotidiano desenvolvida por Bakhtin e que, simplificadamente, pode ser assim compreendida: o pensador russo divide a ideologia do cotidiano em dois níveis, um inferior e outro superior, em que o nível inferior corresponde a uma atividade mental fortuita, isolada, muito mais instável e sem marcação ideológica; já o superior corresponde ao que aqui discutimos sobre ideologia do cotidiano, ou seja, um lugar de maior organização, de acúmulo das transformações e de contato direto com a ideologia oficial.

É no contexto da relação da ideologia oficial e do cotidiano - que se dá em determinada época e em determinado grupo social - que podemos entender a afirmação de Bakhtin de que cada campo de criatividade ideológica tem o próprio modo de se orientar para, e refratar, a realidade; cada campo de atividade e de comunicação humana tem seus modos particulares de representar e de refratar o mundo. Nesse sentido, o autor apresenta dois pontos relevantes de serem estudados no que tange à sociedade como um todo: o conteúdo dos temas que aí se encontram atualizados em dado momento; e os tipos e formas de discursos por meio dos quais estes temas tomam forma, são comentados, se realizam. Os diversos campos de atividade e comunicação da sociedade são ligados pelo uso da linguagem, e o emprego da língua se faz por meio de enunciados concretos e únicos proferidos pelos integrantes de determinado campo. Cada enunciado é individual, mas cada campo elabora seus tipos relativamente estáveis de enunciados: os "gêneros de discurso". Cada época e grupo social têm seu repertório de formas de discurso na comunicação socioideológica, que reflete as condições específicas e as finalidades dos respectivos campos da sociedade. Em todo campo, para que um objeto entre no horizonte social dos sujeitos e desencadeie uma reação semiótico-ideológica capaz de possibilitar o estabelecimento de um canal comunicativo, é indispensável que esse objeto adquira uma significação entre os sujeitos, que estes compartilhem um sentido sobre o objeto.

Bakhtin entende o enunciado como a unidade real da comunicação discursiva, sendo cada enunciado um elo na corrente complexamente organizada de outros enunciados. Ele elabora toda sua teoria no sentido de lutar contra uma visão de ouvinte passivo na comunicação, uma vez que toda compreensão da fala viva, do enunciado vivo, é de natureza ativamente responsiva (embora o grau desse ativismo seja bastante diverso) e toda compreensão é prenhe de resposta: o ouvinte se torna falante. O próprio falante, no contexto comunicativo, está determinado precisamente por essa compreensão responsiva, não esperando uma compreensão passiva que apenas duble o seu pensamento em voz alheia, mas uma resposta, uma concordância, uma participação; e essa compreensão ativamente responsiva não necessariamente se faz em outra fala, ela pode se realizar na ação, como compreensão responsiva silenciosa. 
O que caracteriza um enunciado para Bakhtin é a alternância dos sujeitos do discurso, a sua conclusibilidade e a relação do enunciado com o próprio falante e com outros participantes da comunicação discursiva. Na medida em que há alternância dos sujeitos do discurso, pode-se delimitar um enunciado; isso ocorre porque o falante comunicou tudo o que desejava em dado momento e em certas condições e, do mesmo modo, o ouvinte tem a possibilidade de responder, de ocupar uma posição responsiva em relação a ele. A conclusibilidade do enunciado se faz porque podemos perceber a ideia do autor, seu tema, bem como sua vontade discursiva; desde o início do discurso, percebemos o todo do enunciado em desdobramento, e a vontade discursiva se realiza, primeiramente, na escolha de um gênero de discurso. A palavra dirige-se a um interlocutor: ela é função da pessoa desse interlocutor, de modo que variará de acordo com a posição social e os laços sociais entre os interlocutores. Destarte, o processo de comunicação depende fortemente da escolha do gênero de discurso pelo falante, e a situação dá forma à enunciação, já que a palavra é determinada tanto por proceder de alguém como por se dirigir a alguém.

A escolha dos meios linguísticos e dos gêneros de discurso é determinada pela ideia do sujeito do discurso centrada no objeto e no sentido, que também leva em conta o elemento expressivo, a relação subjetiva emocionalmente valorativa do falante com o conteúdo do objeto e do sentido do seu enunciado, o que estabelece, de certo modo, o estilo. O estilo é o conjunto de procedimentos de acabamento de um enunciado, o conjunto de traços fônicos, morfológicos, sintáticos, semânticos, discursivos etc., que definem a especificidade de um enunciado e, assim, criam um efeito de sentido de individualidade. Quando falamos de gênero de discurso, o conteúdo temático não é o assunto específico de determinado evento, mas é um domínio de sentido de que se ocupa o gênero, o que não significa que não possamos e que não devamos considerar os assuntos específicos que aí circulam.

A palavra, para Bakhtin, está sempre carregada de um conteúdo ou de um sentido ideológico ou vivencial. É dessa maneira que compreendemos as palavras e somente reagimos àquelas que despertam em nós ressonâncias ideológicas ou concernentes à vida. Entretanto, a palavra pode desempenhar papel meramente complementar, uma vez que, graças ao vínculo concreto com determinada situação, a comunicação verbal é sempre acompanhada por atos de caráter não verbal, como um gesto, dos quais ela é muitas vezes apenas o complemento.

Um ponto estruturante da teoria da enunciação bakhtiniana é a consideração da palavra alheia, o dialogismo. Até certo ponto, o caráter dialógico da linguagem foi pontuado anteriormente, mas cabe discuti-lo mais aprofundadamente devido à importância que esse conceito tem para Bakhtin. $O$ dialogismo constitui-se nas relações de sentido estabelecidas entre dois enunciados. Quando escolhemos as palavras no processo de construção de um enunciado, não o fazemos com base na língua em sua forma neutra, lexicográfica, dicionarizada. Na verdade, costumamos tirá-las de outros enunciados; mais que isso, de enunciados congêneres com o nosso, isto é, semelhantes pelo tema, pela composição, pelo estilo. Nosso discurso está impregnado de palavras dos outros, não somos os primeiros nem os últimos na cadeia de comunicação verbal. O enunciado é pleno de tonalidades dialógicas, e, se não as levamos em conta, torna-se impossível entender até o fim o estilo de um enunciado, já que nossa própria ideia - filosófica, científica, artística etc. - nasce e se forma no processo de interação e de luta com as ideias alheias, e isso não pode deixar de encontrar reflexo, também, nas formas de expressão verbalizada do nosso pensamento.

Bakhtin não nega a existência da língua nem condena seu estudo, mas ela não explicaria o fundamento real da linguagem, razão pela qual propõe a criação da translinguística (além da linguística), que teria como objeto o estudo dos enunciados, o exame de suas relações dialógicas, dado que estes são necessariamente dialógicos e, por serem acontecimentos únicos no espaço e no tempo, são irrepetíveis. O enunciado carrega emoção, juízo de valor; já a palavra é neutra. O enunciado tem sentido, que é sempre da ordem dialógica; a palavra tem significação, que é depreendida da relação com outras unidades da mesma língua. Não basta saber o que significa cada uma das unidades da língua que compõem um enunciado para apreender seu sentido; é preciso perceber as relações dialógicas que ele mantém.

O dialogismo, na teoria bakhtiniana, se apresenta em algumas perspectivas. A primeira é o modo de funcionamento real da linguagem, da comunicação: um enunciado se constitui em relação aos 
enunciados que o precedem e aos que o sucedem na cadeia de comunicação. Todo falante da língua é um respondente, pois não é o primeiro a ter violado "o silêncio do universo": usa enunciados antecedentes e formula o seu enunciado já respondendo a uma posição responsiva do interlocutor.

Outra perspectiva dialógica é o fato de o enunciador incorporar o discurso de outrem ao seu, o que vai além da perspectiva anterior, porque estamos tratando do discurso alheio demarcado no nosso, o dialogismo visível. Quando formulamos um enunciado, podemos demarcar o discurso do outro abertamente, por exemplo, com uso de aspas (ou gestos, entonação), o que caracteriza mais objetivamente um discurso direto, criando um efeito de sentido de verdade, mas enfraquecendo, ao mesmo tempo, o fator individual (estilo próprio) do enunciado. A demarcação pode ser mais sutil, por meio do discurso indireto, em que o próprio discurso se apresenta mais individualizado. Há, também, a possibilidade de uma quase fusão de vozes entre o discurso do autor e o do outro, o discurso indireto livre.

A terceira perspectiva, de certo modo, já foi apresentada quando tratamos da consciência como fato socioideológico, em que sua lógica é a da comunicação ideológica, da interação semiótica de um grupo social. O dialogismo é o princípio de constituição do indivíduo e seu princípio de ação. O sujeito, então, se constitui discursivamente ao apreender vozes sociais que conformam a realidade em que se insere e, ao mesmo tempo, suas inter-relações. O sujeito é integralmente social e integralmente singular: cada indivíduo tem uma história particular de constituição de seu mundo interior e interage de modo único com o mundo.

Já abordamos a questão da posição ativa do interlocutor, que é o destinatário direto do diálogo. O enunciador, por exemplo, imagina até que ponto o interlocutor conhece a situação, se deve considerar suas percepções, preconceitos etc. Mas além do destinatário direto, há o sobredestinatário, um terceiro invisivelmente presente - Deus, a moral, a ciência, entre outros -, que também conforma o enunciado produzido. Esta terceira pessoa tem primordial importância, pois é um elemento que reforça a influência das forças sociais sobre o modo de construção e de apreensão do discurso. Portanto, os enunciados de profissionais e dos pacientes/usuários do sistema de saúde não podem ser compreendidos em sua completude sem tomarmos a posição responsiva dos seus (sobre)destinatários.

Outro conceito que fundamenta o pensamento bakhtiniano é a polifonia. A polifonia indica a presença de múltiplos pontos de vista de vozes autônomas não submetidas a um centro de poder. Essas vozes são equipolentes, coexistem e interagem em igualdade de posição. É importante não confundir esse conceito com dialogismo, que trata do funcionamento real da linguagem, o enunciado constituindo-se sempre em relação a outro. Nesse caso, estamos falando da presença de vozes em determinado contexto sem que uma tenha a palavra última e definitiva. Mas podemos presenciar uma plurivocidade (diferentes vozes) sem polifonia, pois há vozes de poder que desejam se impor como centro de sentido, buscando reduzir o plurívoco ao unívoco, configurando "forças centrípetas", diferentemente das "forças centrífugas", que configurariam um evento polifônico.

Concluindo, apresentamos duas categorias que podem ser apreendidas da obra de Bakhtin: intertextualidade e interdiscursividade (não são termos propriamente bakhtinianos, surgiram da divulgação e da compreensão de sua obra). A intertextualidade se confunde com dialogismo, mas enfoca o texto, sendo este a manifestação do enunciado dotada de materialidade. Então, quando encontramos, em um texto, fragmentos de outros que possuem independência de existência, mas que ali se apresentam no processo de construção de sentido, demarcados explicitamente ou não, diz-se que há intertextualidade. Um exemplo disso seria o relato de um paciente sobre sua experiência de adoecimento em que cita, direta ou indiretamente, as sugestões de um vizinho sobre como se tratar; nesse caso, caberia uma análise de como essas sugestões participam na construção dessa experiência.

A interdiscursividade está mais no plano da relação entre gêneros de discurso, pois não se trata de encontrar outro(s) texto(s) específico(s) presente(s) no texto em análise, mas sim de identificar a incorporação de um ou mais gêneros discursivos em outro, o que não se faz de forma demarcada, mas no estilo, na entonação, nos temas, nas formas, como, por exemplo, a incorporação do gênero discursivo militar no familiar, denotando um discurso autoritário dos pais. Independentemente, a interdiscursividade sempre estará presente se pensarmos no funcionamento real da linguagem, em que um discurso sempre sucede e precede outros. 


\section{Construindo a proposta}

Para o objetivo deste ensaio, acreditamos que a discussão apresentada nos fornece subsídios que permitem estruturar uma proposta de referencial metodológico no que tange à comunicação verbal em atividades e processos de educação em saúde, na relação profissional-paciente e em narrativas e experiências de saúde, adoecimento e cuidado. Lembramos que cabe ao pesquisador definir em quais situações, espaços e momentos, utilizar o quadro analítico proposto. As situações que descrevemos foram escolhidas como casos potenciais de uso, exemplos mais evidentes ou elucidativos segundo nosso objetivo.

A seguir, apresentamos o quadro de categorias analíticas elaborado com base na teoria de Bakhtin. A coluna "Conceito" expressa a ideia principal de determinada categoria, mas não a esgota.

Quadro 1. Categorias analíticas baseadas na teoria da linguagem de Bakhtin.

\begin{tabular}{|c|c|}
\hline Categoria & Conceito \\
\hline Sujeitos do discurso & Quem são os agentes (interlocutores) do evento, de onde vêm, o que fazem etc. \\
\hline Objeto & $\begin{array}{l}\text { O que está em discussão no evento e qual a relação com o(s) gênero(s) de discurso } \\
\text { identificado(s). }\end{array}$ \\
\hline Gênero de discurso & $\begin{array}{l}\text { Qual(is) é(são) o(s) tipo(s) de gênero(s) presente(s) no evento: discussão das esferas de } \\
\text { atividade humana e comunicação que o(s) configura(m) e por que esse evento implica a escolha } \\
\text { de determinado(s) gênero(s). Descrição, caso haja claramente mais de um, de como se } \\
\text { relacionam, se integram, como um incorpora o outro. Descrição do conteúdo temático, a } \\
\text { estrutura composicional (essencialmente quando se trata de texto), o estilo. }\end{array}$ \\
\hline Enunciado & $\begin{array}{l}\text { Quais são os enunciados e como eles se formam dentro do contexto comunicativo estudado (as } \\
\text { condiçôes específicas e finalidades da esfera da atividade, os gêneros presentes). Descrição sobre } \\
\text { como se dá a alternância dos sujeitos do discurso, a conclusibilidade. }\end{array}$ \\
\hline Dialogismo & $\begin{array}{l}\text { Quais perspectivas de dialogismo estão presentes: o enunciado se constitui em relação aos } \\
\text { enunciados que o precedem e aos que o sucedem; o discurso incorpora outros discursos, que } \\
\text { podem estar abertamente demarcados ou não, e podem enfraquecer o fator individual do } \\
\text { enunciado ou não; as vozes sociais que constituem o mundo interior do sujeito. Discussão, } \\
\text { dependendo do contexto e objeto (texto), da intertextualidade e da interdiscursividade. }\end{array}$ \\
\hline Destinatário & $\begin{array}{l}\text { Quem são os destinatários e sobredestinatários em relação ao discurso do locutor: descrição de } \\
\text { como eles conformam o enunciado do locutor, a relação com a posição e origem social dos } \\
\text { sujeitos do discurso. }\end{array}$ \\
\hline Responsividade & $\begin{array}{l}\text { Como se dá a posição ativa do ouvinte (interlocutor) e como sua presença influencia o discurso } \\
\text { do outro. }\end{array}$ \\
\hline Vozes & $\begin{array}{l}\text { Quais são as vozes do evento: identificação de diferentes vozes autônomas que não são } \\
\text { submetidas a um centro de sentido, se estas coexistem e interagem em igualdade de posição } \\
\text { (forças centrífugas); identificação de vozes de poder que tentam se impor como centro de } \\
\text { sentido (forças centrípetas). }\end{array}$ \\
\hline
\end{tabular}

Bakhtin entende que, em uma situação de comunicação verbal, é importante atentar ao que chama de "contexto extraverbal", pois só assim podemos compreender como uma palavra ou uma frase, por exemplo, se tornam plenas de significado, se tornam um enunciado. Esse "contexto extraverbal" abrange três fatores: a) o horizonte espacial comum dos interlocutores (a unidade do visível); b) o conhecimento e a compreensão comum da situação por parte dos interlocutores; c) e a avaliação comum que os interlocutores têm da situação. 
Portanto, se tomarmos o exemplo de uma consulta médica, no momento em que o médico fala para o paciente "Bom dia, em que posso te ajudar?", esses interlocutores são conscientes de (e veem) que estão dispostos em uma sala de consulta, do mesmo modo que ambos sabem que o sujeito-paciente está ali porque deve estar com um problema e que o médico deve possuir o conhecimento para enfrentá-lo, enquanto os dois, em certa medida, estão interessados na (e esperam a) resolução do problema.

Para Bakhtin, é deste "conjuntamente visto" (a sala de consulta), "conjuntamente sabido" (alguém tem um problema e alguém pode ajudar a resolvê-lo) e "unanimemente avaliado" (a resolução do problema) que o enunciado depende diretamente; tudo isto é captado na sua real implicação e é o que Ihe dá sustentação.

$\mathrm{O}$ "contexto extraverbal" não é meramente a causa externa de um enunciado; na verdade, a situação se integra ao enunciado como parte constitutiva essencial da estrutura de sua significação. Não entendemos que a análise desses três fatores do "contexto extraverbal" seja obrigatória para a compreensão da situação de interesse, até porque ela pode não ser facilmente aplicada em certos casos, ou mesmo não ser produtiva em outros, mas, de qualquer modo, se configura como relevante etapa analítica em diversas situações. Bakhtin tem em mente, com ela, que um enunciado concreto como um todo significativo compreende dois elementos: o percebido ou realizado verbalmente e o presumido. O presumido é o não-dito, mas que está lá, sustentando, constituindo e sendo constituído pelo dito.

No bojo dessa questão, cabe discutir a posição do observador: o pesquisador. Para Bakhtin, a compreensão dos enunciados integrais e de suas relações dialógicas tem caráter eminentemente dialógico; essa compreensão integra o sistema como elemento dialógico e, de certa maneira, transforma o sentido total. O pesquisador é um participante do diálogo, mesmo que em nível especial, de uma posição absolutamente específica, e é parte dos enunciados a serem interpretados. Aquele que analisa é um respondente aos enunciados em estudo e traz outros enunciados para o âmbito da pesquisa, de modo que dois enunciados distantes um do outro, no tempo e no espaço, que nada sabem um do outro, e com os sentidos confrontados, revelam relações dialógicas se há, ao menos, a convergência de sentidos entre eles. Para Bakhtin, um observador não tem posição fora do observado, e a observação integra o objeto observado como componente.

Destarte, cabe ao pesquisador ter bem clara a sua posição responsiva e dialógica diante da situação comunicativa que estuda; ele está implicado com o objeto pesquisado - de modo diferente dos que participaram da comunicação discursiva estudada, mas está -, o que não significa que isso seja um problema de pesquisa, a não ser que se imagine totalmente distanciado e sem qualquer relação com o objeto. Nesse contexto é que o próprio pesquisador conforma um sujeito do discurso sempre presente, mesmo que de uma posição muito peculiar, com todos os discursos que traz consigo na e para a análise.

Tanto no exemplo anterior da consulta médica quanto em outros - tais como: um farmacêutico construindo com o paciente (ou, até mesmo, impondo) um seguimento farmacoterapêutico; um grupo focal com usuários e profissionais de uma unidade, discutindo sobre as necessidades locais de saúde; um profissional falando sobre sua própria prática; uma pessoa relatando sua experiência de adoecimento; enfim, em todos esses momentos, espaços e situações - a comunicação é elementochave. O modo como essa comunicação se realiza depende, entre outros fatores, de seu objetivo, de quem são os sujeitos, de qual posição ocupam em determinado cenário e de qual cenário se trata.

Em um processo de educação em saúde, o profissional pode estabelecer uma relação de autoridade com o paciente ao assumir o seu conhecimento como verdade absoluta, sem considerar o interlocutor, sua história de vida. É possível que não leve em conta a natureza social daquela atividade, que utilize um gênero discursivo estritamente biomédico no processo educativo em saúde, o qual, muitas vezes, é algo totalmente alheio ao paciente.

Ao contrário, avaliamos que é preciso conhecer esse indivíduo, seus enunciados, os discursos que traz no seio do próprio discurso, os conflitos ou as possibilidades que podem ser gerados pelos discursos de outrem ali integrados. Podemos pensar o profissional de saúde como um professor e o paciente 
5 “...o educador já não é o que apenas educa, mas o que, enquanto educa, é educado, em diálogo com o educando que, ao ser educado, também educa. Ambos, assim, se tornam sujeitos do processo em que

crescem juntos e em que os 'argumentos de autoridade' já não valem[...] os homens se educam em comunhão, mediatizados pelo mundo. Mediatizados pelos objetos cognoscíveis que, na prática 'bancária', são possuídos pelo educador que os descreve ou os deposita nos educandos passivos" (Freire, 2005 . p.79).

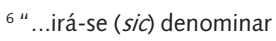
Cuidado essa conformação humanizada do ato assistencial, distinguindo-a daquelas que, por razões diversas, não visam essa ampliação e flexibilização normativa na aplicação terapêutica das tecnociências da saúde [...] adota-se aqui o termo Cuidado como designação de uma atenção à saúde imediatamente interessada no sentido existencial da experiência do adoecimento, físico ou mental, e, por

conseguinte, também das práticas de promoção, proteção ou recuperação

da saúde (Ayres, 2004,

p.22) [...] a busca ativa de projetos de felicidade daqueles de quem se cuida, traz para o espaço terapêutico,

potencializando-o, um processo de

(re)construção identitária que implica mutuamente profissionais e usuários" (Ayres, 2004, p.24-5). como um aluno, pois entendemos que essas situações possuem uma dimensão pedagógica, no sentido de Freire $^{5}$, e uma dimensão cuidadora, no sentido de Ayres ${ }^{6}$.

Quando dissemos que há a dimensão pedagógica em uma situação de saúde, é porque aí também se desenvolve uma troca e a construção de saberes em que os sujeitos crescem juntos; e, dependendo do caso, será sustentada pela centralização do saber técnico na figura do profissional, portanto, sob uma dimensão pedagógica fragilizada. Por sua vez, quando dissemos que há a dimensão cuidadora, é porque aí existe um processo que envolve (re)construções identitárias, imediatamente interessado no sentido existencial da experiência do adoecimento e da prática e, dependendo do caso, será sustentado pela centralização do saber técnico na figura do profissional, portanto, sob uma dimensão cuidadora fragilizada.

O sujeito-paciente pode ou não ter necessidade real de saúde, mas, de todo modo, sempre será alguém na história, um indivíduo dotado de consciência construída de maneira socioideológica, mas única, e com acesso ou não ao gênero discursivo biomédico. Esse sujeito é alguém que experiencia e narra sua situação a seu modo, com palavras suas e alheias, e, ao fazê-lo, espera a compreensão responsiva do outro (p.ex.: o profissional de saúde); por isso, esse outro também é um falante dentro do próprio discurso de quem narra, pois este constrói seu discurso considerando essa posição responsiva do destinatário.

Assim sendo, podemos imaginar o caso de um paciente que, ao elaborar o seu discurso, termine por construir o relato de sua experiência de adoecimento não da forma como a compreende e a expressa concretamente, no cotidiano, mas de acordo e respondente à posição de autoridade detentora do conhecimento desempenhada pelo profissional de saúde. Nesse exemplo, é evidente a ausência de polifonia; há, ao contrário, um discurso monológico (forças centrípetas), em que uma voz de poder deseja se impor como centro de sentido. Até que ponto a relação profissional-paciente não transforma a própria experiência de adoecimento (sua compreensão e expressão) que o sujeito vive no dia a dia?

Entretanto, as categorias que apresentamos não servem apenas como referencial de análise; julgamos que podem servir de base à construção de espaços e de atividades em que o dialogismo polifônico seja o fundamento. Por exemplo, uma unidade que realize encontros entre profissionais e usuários, com uma proposta educativa sobre algum tema específico ou com o objetivo de discutir problemas relacionados à organização e às demandas locais do serviço, pode estruturá-los de modo que não haja vozes de poder que se imponham como centro de sentido. Os encontros podem ser pensados para se fazerem presentes múltiplos pontos de vista de vozes autônomas, não submetidas a um centro, coexistindo e interagindo em igualdade de posição.

Para além, pode-se propor um espaço em que os sujeitos se reconheçam não somente como autônomos, no sentido de possuírem singularidades, de terem experiências e/ou saberes próprios e sem hierarquia entre si, mas que se reconheçam, ao mesmo tempo, como iguais, no sentido de que todos, sem exceção, constroem suas experiências e saberes na relação com o outro em verdadeiro dialogismo, se apropriando e transformando o discurso do outro. Cada sujeito ali presente não será o primeiro nem o último na cadeia de comunicação verbal, responderá a um enunciado anterior e produzirá o próprio enunciado em relação à posição respondente do outro, seja ele o vizinho, o profissional de saúde ou o grupo como um todo. 
Nesse sentido, cada enunciado é único e de todos ao mesmo tempo, posto que cada indivíduo tem uma história particular de constituição de seu mundo interior e interage de modo único com o mundo. O sujeito é integralmente social e integralmente singular.

Poderíamos nos estender a outros exemplos possíveis em que nossa sugestão teria utilidade potencial, mas cabe reafirmar, nas linhas restantes, que esse é mais um referencial que se soma aos outros tantos para esse tipo de pesquisa ou projeto; apenas nos propusemos a colaborar com o campo. Nossa proposta apresenta limites, entre eles, o fato de não ser útil, linearmente, a uma análise de comunicação não verbal, comunicação esta que adquire crucial importância em um mundo mediado por imagens e em um campo, como a saúde, em que o contato humano, gestos e outros modos não verbais de comunicação têm relevância inquestionável.

Lembramos, por fim, que as categorias apresentadas não dão conta de toda a teoria de Bakhtin, teoria que consideramos de riqueza inestimável (e que vai além do aqui discutido), sobretudo por não se limitar a uma análise que se fixa ou no extremo estruturalista ou no extremo subjetivista. Ao contrário, trabalha essas duas dimensões de modo relacional, pois, afinal, somos todos e somos únicos.

\section{Colaboradores}

Guilherme Torres Corrêa responsabilizou-se pela redação do artigo. Victoria Maria Brant Ribeiro responsabilizou-se pela revisão.

\section{Referências}

AMORIM, M. Vozes e silêncio no texto de pesquisa em ciências humanas. Cad. Pesqui., n.116, p.7-19, 2002.

AYRES, J.R.C.M. O cuidado, os modos de ser (do) humano e as práticas de saúde. Saude Soc., v.13, n.3, p.16-29, 2004.

BAKHTIN, M.; VOLOCHINOV, V.N. Marxismo e filosofia da linguagem. São Paulo: Hucitec, 1981.

BAKHTIN, M. Os gêneros do discurso. In: (Org.). Estética da criação verbal. Trad. Paulo Bezerra. São Paulo: Martins Fontes, 2003a. p.261-306. O problema do texto na linguística, na filologia e em outras ciências humanas. In: (Org.). Estética da criação verbal. Trad. Paulo Bezerra. São Paulo: Martins Fontes, 2003b. p.307-35. Metodologia das ciências humanas. In: (Org.). Estética da criação verbal. Trad. Paulo Bezerra. São Paulo: Martins Fontes, 2003c. p.393-410. FIORIN, J.L. Introdução ao pensamento de Bakhtin. São Paulo: Ática, 2006. FREIRE, P. Pedagogia do oprimido. 44.ed. Rio de Janeiro: Paz e Terra, 2005. VOLOSHINOV, V.N.; BAKHTIN, M.M. Discurso na vida e discurso na arte (sobre a poética sociológica). Disponível em: <http://www.fflch.usp.br/dl/ noticias/downloads/Curso_Bakhtin2008_Profa.\%20MaCristina_Sampaio/ ARTIGO_VOLOSH_BAKHTIN_DISCURS̄O_VIDA_ARTE.pdf $>$. Acesso em: 20 maio 2011. 
CORRÊA, G.T.; RIBEIRO, V.M.B. Dialogando con Bakhtin: algunas contribuciones para la comprensión de las interacciones verbales en el campo de la salud. Interface Comunic., Saude, Educ., v.16, n.41, p.331-41, abr./jun. 2012.

Con base en la idea de que las necesidades de, y las intervenciones en la salud son condiciones y acciones humanas permeables y construídas por actos comunicativos, se discuten categorías centrales del pensamiento del filósofo del lenguaje Mikhail Bakhtin - tales como: dialogismo, enunciado, género, polifonía - como base de un marco analítico de interacciones verbales en el campo de la salud. Bakhtin desarrolla un pensamiento cuyo fundamento es la naturaleza social del lenguaje, entendiendo que la comunicación de cada época y grupo social refleja las condiciones específicas y los fines de los respectivos campos de la sociedad. Para él, el sujeto se constituye

discursivamente aprehendiendo voces ajenas y es integralmente social y singular. Tomando como referencia esa constitución social y singular de los individuos, se presenta, de forma seminal, una proposición práctica para la construcción de espacios y de actividades en el campo de la salud.

Palabras clave: Bakhtin. Lenguage. Comunicación. Interacciones verbales. Salud. 
